\title{
EDUCAÇÃO E DEMOCRACIA. DISCURSOS SOBRE A UNIVERSIDADE PORTUGUESA EM TEMPOS DE TRANSIÇÃO (1974-1976) ${ }^{1}$
}

DOI: http://dx.doi.org/10.1590/2236-3459/76890

\author{
Helder Henriques
}

Instituto Politécnico de Portalegre, Portalegre/Portalegre, Portugal

$\cos 8$

\begin{abstract}
Resumo
A Revolução portuguesa do 25 de Abril de 1974 constituiu o inicio de uma nova vaga democratizadora (Huntington, 1993). Partindo deste pressuposto procuramos discutir o processo de transição de um regime político autoritário (o Estado Novo) para um regime democrático em Portugal (1974-1976). Tratamos especificamente das problemática educativas neste período, com maior incidência sobre as instituições universitárias. Com efeito, procurou-se identificar, discutir e interpretar os discursos associados à universidade portuguesa num período rico, mas conturbado, da História da Educação Contemporânea. Optamos por uma abordagem metodológica qualitativa cujo trabalho empírico foi baseado, principalmente, na imprensa periódica diária, em particular no Diário de Lisboa (1921-1990). A análise deste periódico permitiu colocar em evidência um conjunto de discursos que circularam no interior das instituições universitárias da época possibilitando compreender o modo de apropriação das ideias em circulação naquele tempo e perceber o seu papel no novo regime político.
\end{abstract}

Palavras-chave: transição, democracia, educação, imprensa, Portugal.

\section{EDUCATION AND DEMOCRACY. DISCOURSES ABOUT PORTUGUESE UNIVERSITY IN TIMES OF TRANSITION (1974-1976)}

\begin{abstract}
The Portuguese Revolution of 25 April 1974 constituted the beginning of a new wave of democratization (Huntington, 1993). Based on this assumption we try to discuss the process of transition from an authoritarian political regime (the Estado Novo) to a democratic regime in Portugal (1974-1976). We deal specifically with the educational problems in this period, with a greater incidence on university institutions. In fact, we sought to identify, discuss and interpret the discourses associated with the Portuguese university in a rich but troubled period of the History of Contemporary Education. We opted for a qualitative methodological approach whose empirical work was based mainly on the daily periodic press, particularly in the Diário de Lisboa (1921-1990). The analysis of this journal made it possible to highlight a set of discourses that circulated within the university institutions of the time making it possible to understand the way of appropriation of the ideas in circulation at that time and to perceive their role in the new political regime.
\end{abstract}

Keywords: transition, democracy, education, press, Portugal.

\footnotetext{
${ }^{1}$ Este texto faz parte de um projeto mais amplo, que tem como objetivo analisar os processos de construção de imaginários pedagógicos coletivos através da imprensa diária em tempos de mudança política e social na Europa Mediterrânica e Ibero-América, desenvolvido pelo Grupo de Investigação da Universidade de Valladolid (Espanha) Ágora de Educación (http://www.agoradeeducacion.com).
}

\begin{tabular}{|l|l|l|l|l|r} 
Hist. Educ. (Online) & Porto Alegre & v. 22 & n. 54 & jan./abr. 2018 & p. 71-90
\end{tabular}




\title{
EDUCACIÓN Y DEMOCRACIA. DISCURSOS SOBRE LA UNIVERSIDAD PORTUGUESA EN TIEMPOS DE TRANSICIÓN (1974-1976)
}

\begin{abstract}
Resumen
La Revolución portuguesa del 25 de Abril de 1974 representa el inicio de una nueva oleada democratizadora (Huntington,1993). Partiendo de este presupuesto pretendemos discutir el proceso de transición de un régimen político autoritario (el Estado Nuevo) a un régimen democrático en Portugal (1974-1976). Nos centramos en las problemáticas educativas asociadas a las instituciones universitarias donde se procuró identificar y analizar las principales líneas discursivas en el arco temporal ya señalado. Optamos por un abordaje metodológico cualitativo cuyo trabajo empírico se basó, principalmente, en la prensa periódica diaria, en particular en el Diário de Lisboa (1921-1990). El análisis de este periódico permitió poner en evidencia un conjunto de ideas que circularon en esas instituciones con repercusiones en la opinión pública en una época de transición para la democracia.

Palabras clave: transición, democracia, educación, prensa, Portugal.
\end{abstract}

\section{ÉDUCATION ET DÉMOCRATIE. DISCOURS SUR L'UNIVERSITÉ PORTUGAISE EN TEMPS DE TRANSITION (1974-1976)}

\section{Résumé}

La Révolution portugaise du 25 avril 1974 marque le début d'une nouvelle vague démocratisante (Huntington, 1993). En partant de ce pésupposé, nous prétendons discuter le processus de transition d'un régime politique autoritaire (l'État Nouveau) à un régime démocratique au Portugal (1974-1976). Nous avons centré notre étude sur les problématiques éducatives associées aux institutions universitaires, en cherchant à identifier et à analyser les principales lignes discursives présentes dans la période temporelle signalée plus haut. Nous avons opté pour un abordage méthodologique qualitatif, dont le travail empirique s'est basé principalement sur la presse périodique quotidienne, en particulier le Diário de Lisboa (1921-1990). L'analyse de ce périodique a permis de mettre en évidence un ensemble d'idées qui ont circulé dans ces institutions, et ont eu des répercussions dans l'opinion publique à une époque de transition vers la démocratie.

Mots-clés: transition, démocratie, éducation, presse, Portugal. 


\section{Introdução}

A $s$ últimas décadas da centúria de novecentos podem caraterizar-se como um período de transformações no Ocidente e América Latina decorrentes de uma "onda democratizadora" que, de acordo com Huntington (1993), se iniciou em Portugal ao som de "Grândola - Vila Morena". Através deste sinal, emitido pela rádio, as tropas partiram para a capital portuguesa - Lisboa - com o objetivo de derrubar um regime autoritário instalado no país há muitas décadas. Após a queda do Estado Novo iniciou-se um momento de transição para a democracia - começava a "terceira onda de democratização". (HUNTINGTON, 1993, p. 3).

Os processos de transição entre regimes políticos constituem sempre momentos de questionamento e mudança. Por um lado, questiona-se aquilo que foi a proposta política, nas suas várias dimensões, do regime anterior; por outro lado, procuram-se implementar novas conceções sociais, económicas e políticas de acordo com o novo projeto para uma determinada sociedade. Em todos estes processos o lugar da Educação é central e constitui motivo de preocupação por parte daqueles que pretendem implementar e/ou construir uma nova sociedade. No mesmo sentido, também a imprensa constitui um elemento relevante no processo de transição para um novo regime politico uma vez que é um elemento participante no processo de implementação de novas ideias e valores.

Partimos deste pressuposto e da articulação da importância da Educação e da Imprensa para tentarmos compreender melhor o processo de transição para a democracia em Portugal, num arco temporal que se desenvolve entre a Revolução de 25 de Abril de 1974 e a votação da Constituição do regime democrático Português, em Abril de 1976. Para o efeito, colocamos algumas questões de partida, orientadoras do nosso trabalho: Que projeto social e educativo se procurou construir, de acordo com a imprensa diária, no período de transição política para a democracia? Que lugar, segundo a imprensa diária, ocuparam as universidades nesse processo? Que discursos relacionados com o tecido universitário português circularam na imprensa?

Do ponto de vista teórico, ancoramos o presente trabalho ao campo científico das ciências sociais e humanas e, em particular, da História da Educação. Mobilizamos autores diversos (BOURDIEU, 2014; TORGAL, 2015; HERNÁNDEZ HUERTA; GONZÁLEZ GÓMEZ, 2014; HERNÁNDEZ HUERTA; ORTEGA GAITE, 2015; FERREIRA, 1992; PINTASSILGO, 2015; XAVIER, 2013; AVRITZER, 1995; TEODORO, 2003; VALENTIM, 1997; GRÁCIO, 1975/1995; FERNANDES, 1977; entre outros) que permitiram colocar a discussão em três níveis: um primeiro nível relacionado com as problemáticas conceptuais; um segundo nível, procurando-se relacionar educação e democracia; e um terceiro nível onde se valorizou, principalmente, os discursos associados especificamente à "questão universitária" em Portugal.

A imprensa diária - em particular o periódico Diário de Lisboa - assume-se aqui como a principal fonte de informação. Consultamos todas as edições publicadas pelo Diário de Lisboa entre Abril de 1974 e Abril de 1976. Foram percorridas mais de 600 edições daquele periódico (aproximadamente 12.200 páginas). A sua escolha prende-se com o facto de se encontrar próximo do principal palco da ação no processo de transição revolucionária: em Lisboa, capital portuguesa; e, ainda, pela facilidade que dispúnhamos na consulta do mesmo realizada através da Fundação Mário Soares que disponibilizou, em formato digital, todas (ou quase todas) as edições do Diário de Lisboa, desde a sua 
fundação (1921) até ao ultimo número publicado (30 de novembro de 1990).

O corpus documental é, portanto, constituído por cerca de 300 (294) textos (artigos diversos, entrevistas, editoriais, etc.) relacionados com o grande tema "Educação". Neste contexto, identificamos cerca de 70 textos que tratavam especificamente das problemáticas relacionadas com a Universidade portuguesa e que tentamos analisar detalhadamente numa perspetiva qualitativa. Na verdade, acompanhamos Hernández Huerta e Gonzalez Gomez (2014) quando afirmam a relevância da imprensa para os Historiadores da Educação como um:

[...] amplio campo de investigacion escasamente atendido por los historiadores de la educacion, un material con dimensiones, calado, valor y potencial explicativo aun por determinar. Acometer el estudio de la documentacion mencionada durante el tiempo de la transicion a la democracia significa explorar algo por vez primera, como se suele decir comunmente, 'pisar nieve virgen. Ahi radican la novedad y la originalidad del trabajo que aqui se presenta y, por extension, de la linea de investigacion dada a conocer; tambien la necesidad de abordar el analisis pormenorizado, riguroso y sistematico de los contenidos sobre educacion aparecidos en los periodicos durante un momento en el que se modifico notablemente la trayectoria [...]. (HERNÁNDEZ HUERTA; GONZALEZ GOMEZ, p. 182).

Do ponto de vista metodológico, optou-se por realizar um trabalho de natureza socio histórica com recurso à análise documental e de conteúdo na medida em que este método coloca em "crise" a documentação, obriga à sua triangulação e assim à sua validação enquanto fonte. Iniciamos este processo com a seleção do recorte temporal em análise, a identificação dos textos com interesse para a construção do presente artigo, a categorização dos textos e a sua análise e, por fim, a escrita do mesmo.

Defenderemos, ao longo do texto, que o processo de transição configura um contexto ideal de mudança na medida em que se encontram em conflito "concepções autoritárias e expectativas democratizantes, [...] movimentos organizados de contestação ao poder e tentativas governamentais de conduzir, sob seu próprio controle, as mudanças políticas requeridas naquela conjuntura". (XAVIER, 2013, p. 241). A educação, em particular o ensino superior, constituiu um elemento com forte presença desde o final do regime político do Estado Novo - onde os movimentos estudantis tiveram um papel destacado no processo que levou à queda do regime - até à instituição formal da democracia portuguesa. Nesse período de transição procurou-se construir uma sociedade caraterizada pelo socialismo democrático onde às Universidades era atribuído um papel central no processo de mudança para a democracia, verificando-se nesse palco muitas das problemáticas relacionadas com as "lutas de classes".

\section{Estado e Transição para a democracia: problematizar uma ideia}

A reflexão sobre os processos de transição existentes ao longo da modernidade implica algumas considerações prévias sobre aquilo que entendemos em relação ao papel e funções do Estado. Partimos do principio que o Estado, no seguimento da argumentação de Bourdieu (2014), é um campo de poder administrativo e burocrático que permite a fundamentação moral e lógica de uma determinada sociedade agindo sobre a mesma através de um "monopólio da violência física e simbólica legitima". (ibidem, p. 16). Este princípio de definição proposta pelo sociólogo francês, apoiado em Max Weber, permite 
afirmar a importância do Estado enquanto elemento definidor de valores promotores de consenso social de onde emergem, depois, conflitos sociais. Como afirma Bourdieu (2014) "para que o próprio conflito sobre o mundo social seja possível, é necessário haver uma espécie de acordo sobre os terrenos de desacordo e sobre os modos de expressão do desacordo". (BOURDIEU, 2014, p. 17). Na verdade, acompanhamos o autor quando afirma que o Estado é um campo de poder com regras definidas e valores pressupostos que implicam o consentimento dos indivíduos mobilizando, entre outros aspetos, o tempo, a sua capacidade de produção discursiva, orientando os espaços públicos e privados e canonizando princípios fundamentais ao bom funcionamento da sociedade. Estas considerações estão presentes em permanência no quotidiano social mas, com maior destaque e expressão em momentos de convulsão política, económica e/ou social. É o caso dos processos de transição ocorridos, por exemplo no século $X X$ onde os meios de comunicação, em particular a imprensa diária nacional, alimentaram um conjunto de ideias fundamentais à mudança de princípios, mandatos e categorias estatais decorrentes da emergência de novas formas de interpretação do Estado por novos regimes e protagonistas políticos.

Assim, os processos de transição para a democracia que, ao longo dos anos $70 \mathrm{e}$ 80 do século XX, foram eclodindo pela Europa e América Latina, permitem-nos identificar, do ponto de vista conceptual, um conjunto de etapas gerais presentes nestes ciclos de mudança que podem assumir várias configurações de acordo com diversas variáveis (realidades geográfica, cultural, política, etc.). Tal como afirma Xavier (2013):

As reconfigurações no sistema político apresentam-se como oportunidades para ensaiar mudanças, experimentar alianças, conquistar direitos. Deve-se levar em conta, contudo, os mecanismos identitários que desencadeiam esse processo, já que este depende da capacidade dos atores ou de suas lideranças identificarem os sinais, os acontecimentos que indicam uma possível oportunidade. Tal identificação pode derivar de uma declaração do Governo ou da manifestação de outros grupos que apontam para a existência das oportunidades políticas, promovendo-se um jogo de leituras e desencadeando uma bola de neve de movimentos e manifestações coletivas. (2013, p. 218).

Para procurarmos identificar as etapas destes processos de mudança partimos de uma inquietação relacionada com o significado que pode ter a ideia de transição para a democracia, baseados na análise do caso português.

Em nosso entender, esta ideia - transição para a democracia - implica três dimensões articuladas entre si que permitem uma leitura mais crítica: em primeiro lugar, o reconhecimento da existência de um regime autoritário constituído por mecanismos de poder específicos que colocavam em causa e condicionavam amplamente a ação individual; em segundo lugar, a rotura, mais ou menos consciente, com o regime autoritário, num momento determinado, resultado de descontentamento generalizado à luz de pressupostos sociais e político-ideológicos, desenvolvidos ainda no interior do regime cessante, capazes de convocar aqueles que detinham o poder das armas e derrubar o regime então vigente; em terceiro lugar, a reconfiguração após a queda do regime ditatorial, do Estado, da Sociedade, das suas organizações e protagonistas, procedendo a um amplo movimento de saneamento das estruturas de poder consideradas não democráticas e, neste sentido, procurando substituir essas estruturas ou lugares por indivíduos associados aos novos princípios ideológicos. Ao longo deste texto, centrar-nos-emos com maior 
incidência nesta ultima dimensão.

Consideramos que a transição para a democracia deve ser interpretada como um momento multidimensional, relativamente delimitado no tempo, mas com dinâmicas prévias, onde se evidenciam relações de poder, com avanços e recuos, num projeto social e político que se pretende instalar e, por conseguinte, implica análises complexas sobre os processos relacionados com o Estado, as relações de poder entre o Estado e a Sociedade e os modos como se difundiam os novos princípios ideológicos, e afastavam os anteriores, num momento de mudança, no caso português, para um regime político Democrático. Deste modo, na perspetiva de Avritzer (1995), apoiado em O’ Donnell \& Schimtter (1986), a ideia de transição:

[...] consiste no intervalo entre um regime político e outro [...] As transições são geralmente delimitadas, por um lado, pelo lançamento de um processo de dissolução de um regime autoritário e, pelo outro, pela instauração de alguma forma de democracia, pelo retorno a alguma forma de regime autoritário ou pela emergência de uma opção revolucionária. (1986, p. 6).

No caso Português, este intervalo entre regimes pode ser delimitado ao período que corresponde à queda formal do regime político do Estado Novo, a 25 de Abril de 1974 e, por outro lado, ao momento da aprovação da atual Constituição Portuguesa, em Abril de 1976. É, principalmente, a este período que podemos chamar de transição para um regime Democrático. Efetivamente, foi a partir da Revolução do 25 de Abril de 1974, e posteriormente com o Processo Revolucionário em Curso (Prec), que se operou a inevitável mudança para o sistema político democrático, pese embora o influente papel das organizações políticas que viviam na clandestinidade no interior do regime autoritário. A institucionalização de um regime político democrático, assente em valores como a igualdade e/ou a liberdade, materializou-se em Portugal com a Revolução dos Cravos, como ficou conhecida, e mereceu consenso entre as forças militares e civis da época. É pela singularidade do caso português na década de 70 do século XX, que Torgal (2015) afirma estarmos perante uma:

Revolução militar [que] teve, no entanto, um apoio popular e desenvolveu-se não só devido ao Movimento das Forças Armadas (MFA), mas aos partidos já existentes na clandestinidade, o Partido Comunista Português, cujo secretário-geral era Álvaro Cunhal, e o Partido Socialista, de Mário Soares, já que os outros principais partidos só vieram a organizar-se posteriormente, ainda que antes existissem também algumas formações de esquerda radical. (2015, p. 159).

Portanto, a especificidade do caso português permite-nos falar num processo de transição revolucionária para a democracia cuja origem não se corporiza apenas no movimento militar do 25 de Abril de 1974, mas também foi resultado de um processo político-partidário, embora clandestino, que ocorreu no interior do próprio regime ditatorial e que, posteriormente ao dia 25 de abril de 1974, foi particularmente importante no processo de transição para a democracia portuguesa. A este propósito, Pintassilgo (2014) é perentório quando afirma que:

[...] o impacto que o 25 de Abril de 1974 teve como momento-chave da transição para um novo período da nossa história e, em particular, como o acontecimento mais marcante da transição portuguesa para uma democracia política, convém ter em conta todo um amplo conjunto de transformações subterrâneas, que 
preencheram esses anos e que tornaram possível a eclosão desse momento tão significativo do ponto de vista simbólico. (2014, p. 14).

De facto, o período que antecede a Revolução de 25 de Abril de 1974 caraterizouse por graves problemas económicos e sociais decorrentes, em grande medida, da falência de um regime que fomentava e enfrentava uma guerra colonial. Como afirma Pintassilgo (2014):

A década e meia que antecedeu a revolução testemunhou uma guerra colonial, o
desaparecimento físico de Salazar e a sua substituição por Marcelo Caetano, uma
tímida tentativa de abertura política logo seguida pelo endurecimento do regime até
ao beco sem saída e ao isolamento internacional da fase final, a eclosão de fortes
movimentos de contestação nos meios universitário, intelectual e operário. Mas
esse foi, também, um período marcado por uma tentativa de industrialização, pela
migração de populações rurais para a periferia das grandes cidades e pelo
crescimento e concentração do operariado. Foi, finalmente, uma época de abertura
cultural e mental, por via do desenvolvimento turístico, da emigração para outros
países da Europa, da chegada de novas correntes artísticas e de estilos de vida
alternativos. Estas mudanças invisíveis tornaram anacrónica a mundividência
católica, ruralista, patriótica e colonial que caracterizara o salazarismo e foram
minando, pouco a pouco, as bases do regime autoritário. (2014, p. 14).

Estes acontecimentos foram permitindo construir e lançar as bases para um processo de mudança que haveria de encontrar um momento de viragem na revolução de 25 de Abril de 1974. No fundo, aquilo que esteve em causa no processo de transição para o regime democrático em Portugal foi a alteração de um modelo social, político e económico autoritário para um modelo de desenvolvimento assente numa cultura política de negociação permanente, onde todos os indivíduos deveriam ser considerados iguais, com direito à liberdade e expressão do pensamento, a que o sistema educativo e, em particular, a Universidade portuguesa não foram alheios. (TORGAL, 2015, p. 160).

Todavia, não ignoramos que estas opções políticas não estiveram isentas de contestação, sobretudo por aqueles que não se reconheciam nas mesmas. (AVRITZER, 1995). Não é por acaso que na imprensa nacional surgem notícias ou artigos de opinião que fazem referência, entre outros, à necessidade de combater a presença de resquícios autoritários, por exemplo, nas escolas, nos manuais escolares e nas organizações educativas. A título de exemplo, Manuela Alves escreve no Diário de Lisboa um artigo de opinião com o seguinte título "Contrariando o processo de democratização - Manuais do Ensino Primário Servem a Causa do Fascismo" onde afirma em relação aos manuais de História o seguinte:

[...] os livros mais "completos" no seu espírito anti-portugal de hoje são a História de Portugal de João e Armando Pimenta [...] e a História da 4 $4^{a}$ classe de J. Baptista Martins e A. Matos Gonçalves. A primeira publica lado a lado, duas fotografias de Américo Tomás no dia 10 de Junho com as seguintes legendas: "O senhor presidente da República a condecorar um herói branco". [...] A História da 4⿳亠丷a classe [...] publica na página 77 esta outra violenta agressão ideológica: "De entre os portugueses ilustres da actualidade distingue-se o Dr. António de Oliveira Salazar. Durante mais de 40 anos devotou inteiramente, ao Governo do nosso país toda a sua inteligência e todo o seu saber". (ALVES, 11 de Outubro de 1974, p. 11).

Ora, estes problemas são referidos ao longo do período de transição revolucionária para a democracia (1974-1976). A citação anterior serve também para chamarmos à 
discussão a centralidade da Educação no processo de democratização da sociedade portuguesa. Efetivamente, as problemáticas educativas foram colocadas em plano principal na discussão politica e social da época. A Revolução e o processo de transição para a democracia chegaram e entraram na Escola.

\title{
Educação e Democracia em tempos de transição revolucionária (1974 - 1976)
}

Nesta fase inicial da construção revolucionária da democracia portuguesa, a Educação constituiu um campo de lutas e tensões da maior importância para a institucionalização do novo regime em Portugal. O sistema educativo podia constituir o veículo mais relevante para a construção de uma sociedade nova que pretendia emanciparse de um passado demasiado vincado. Neste campo, como afirma Teodoro (2003), a revolução colocou os problemas educativos no centro do debate político e social. Assim:

A educação, nesse período de crise revolucionária, para além de um aceso palco de lutas políticas, tornou-se um campo privilegiado de legitimação da nova situação democrática, apostada em mostrar, e não apenas ao nível do discurso político, uma radical mudança face às anteriores políticas obscurantistas do Estado Novo. [...] cedo se caminhou para a tentativa de formular um programa que, no campo da educação, respondesse ao propósito, então largamente consensual ao nível do discurso político, de construir uma sociedade a caminho do socialismo. (TEODORO, 2003, p. 134).

A preocupação com a importância da educação no processo de institucionalização da democracia em Portugal é expressa de modo evidente, entre outros, no Programa de ação do Ministério da Educação e Investigação Cientifica (Meic) do IV Governo Provisório. Neste programa afirmava-se que "as tarefas do ensino estão entre as tarefas prioritárias da revolução portuguesa" e, por isso, assumia-se a necessidade de abrir a escola à comunidade, adequá-la às necessidades sociais e promover o acesso aos "filhos das classes mais desfavorecidas". (Meic, Programa de Acção, 1975, ponto I).

\begin{abstract}
São estes os vários sentidos do objetivo número um da política da educação - a democratização do ensino. Democratizar a escola é, portanto: (a) abri-la a todas as camadas sociais e regionais, privilegiando, para já, o acesso à Escola das classes trabalhadoras e das populações rurais, (b) pô-la ao serviço dos reais interesses do povo português na sua marcha para o socialismo e para a completa independência nacional e, (c) fazer intervir decisivamente na elaboração da política escolar todas as entidades interessadas no processo revolucionário e não apenas a comunidade escolar "corporativa" de professores e alunos. (ibidem).
\end{abstract}

A Escola transformou-se numa arena política onde os atores educativos, os sindicatos, entre outros, apresentavam as suas reivindicações, ocupavam as instituições escolares, perseguiam determinados professores associados a práticas ou ideias relacionadas com o regime anterior. Enfim, um imenso palco de lutas sociais e políticas. Mas, havia que pensar a Escola como um elemento capaz de promover a desejada sociedade socialista e para isso era necessário que no seu todo se trabalhassem alguns aspetos com maior cuidado, nomeadamente:

A prática social como condição fundamental para a correcta formação de consciência social do aluno; Uma educação que consciencialize o aluno de que o seu trabalho é socialmente útil e que se produz um valor social; $A$ formação de crianças e do jovem directamente integrada na produção através da combinação 
adequada ao estudo com o trabalho produtivo; $A$ integração cada vez maior entre trabalho intelectual e trabalho manual; A educação realiza-se, antes de tudo, através do trabalho físico quando directamente ligado ao pensamento, à iniciativa pessoal e à integração na tarefa colectiva vivida em comum; $\mathrm{A}$ interligação entre os planos de desenvolvimento nacional e regional como uma das formas de consolidar a pedagogia socialista, a ligação da Escola com as necessidades de desenvolvimento do País será o meio mais correcto de promover a sua profunda transformação; O desenvolvimento da consciência responsável da criança e do jovem, numa verificação constante de que o próprio processo educativo é o resultado do sacrifício diário realizado pelas massas trabalhadoras para conquistarem os meios indispensáveis ao seu funcionamento. É dentro destas perspectivas que se deve inserir a real democratização da Escola Portuguesa em ordem à constituição de uma verdadeira pedagogia socialista. (ibidem, ponto VIII).

A citação anterior remete-nos para um conjunto de aspetos aprofundados durante o Prec. Referimo-nos, entre outros, à unificação do ensino secundário; à criação da educação cívica politécnica ou às atividades de contacto que foram implementadas no período em análise numa perspetiva de aproximação entre a escola e a comunidade. Além destas iniciativas, destacamos a gestão democrática das instituições escolares tornando a Escola, no seu conjunto, um "espaço onde se projetavam os interesses de três comunidades (escolar, local e nacional)" com vista à produção de indivíduos com autonomia. Não obstante, o elemento estruturante do período revolucionário foi a promoção da igualdade de oportunidades isto é, não apenas o acesso à Escola mas também o sucesso ao longo do percurso escolar. (VALENTIM, 1997). A ideia de "Escola para todos" encontrava-se bem vincada nos discursos políticos e pedagógicos da época em análise. Como referem Pintassilgo \& Mogarro (2003):

A igualdade de oportunidades no sistema escolar foi uma questão central da democratização do ensino nos anos revolucionários - registava-se um elevado número de crianças que estavam excluídas da escola, assim como taxas de analfabetismo que se situavam acima dos trinta por cento. $O$ alargamento da escolaridade obrigatória defrontava o sistema com o abandono precoce da escola por parte dos alunos, que não terminavam o ciclo de vida escolar legalmente estabelecido. O problema não era apenas promover o acesso a todos os níveis de ensino, mas garantir a escolarização efectiva e com sucesso das jovens gerações portuguesas. (2003, p. 13).

No mesmo sentido Grácio (1975/1995) e Fernandes (1977) afirmavam que a problemática da igualdade de oportunidades constituía uma questão fundamental naquele período associado à transição para a democracia em Portugal. Neste contexto destacouse, com grande visibilidade na opinião pública, a questão do acesso ao ensino superior. $O$ IV Governo Provisório, atribuía-lhe especial responsabilidade na missão de colaborar no desenvolvimento tecnológico, científico e cultural do País porque só desse modo se poderia ambicionar "conquistar uma completa independência nacional" (Meic, Programa de acção, 1975, ponto 3.3.). Tornava-se, portanto, indispensável que "as universidades se comprometam claramente em programas concretos de apoio técnico e cientifico às diversas actividades sociais, pondo directamente ao serviço do povo português recursos que são seus" (Idem) evitando a importação de tecnologias estrangeiras. Sobre o "atraso" da universidade portuguesa Nóvoa (1992) defende que no Estado Novo:

Em termos globais, o sistema de ensino superior denota uma baixa produtividade, o que agrava alguns dos estrangulamentos e deficiências [...] assinalados: é provável que apenas cerca de um terço dos estudantes que ingressaram nas 
universidades em 1960 terminem os seus cursos. A eficiência externa do sistema universitário também é bastante limitada, contribuindo para manter uma estrutura das qualificações da população activa incompatível com o ritmo de progresso científico, tecnológico, socioeconómico e cultural necessário ao desenvolvimento do país. (1992, p. 495).

Desde meados da década de 60 do século $X X$ que um conjunto de intelectuais (Adérito Sedas Nunes, Miller Guerra, etc.), chamavam a atenção para a necessidade de modernizar a Universidade Portuguesa. (HENRIQUES; MARCHÃO; MOURATO, 2015). Ao longo do período de transição para a democracia a universidade transformou-se num lugar de enorme circulação de ideias, movimentações políticas, influências e dinâmicas diversas. Neste particular, tiveram importância central as movimentações estudantis. A imprensa dános conta de uma fase inicial muito propícia a intensas atividades de contestação em relação a tudo o que pudesse ter alguma ligação com o regime político anterior. A título de exemplo recuperamos uma noticia do Diário de Lisboa, publicada a 30 de abril de 1974 (apenas 5 dias depois da queda do regime autoritário), relacionada com a Universidade de Coimbra que antecipa aquilo que aconteceu nos meses seguintes:

\begin{abstract}
O encerramento da Universidade foi devido ao facto de o reitor ter tido conhecimento de que estava preparado para ontem um plenário da Academia para o pátio da Universidade no sentido de solicitar a demissão do reitor e mais autoridades académicas. Em virtude de o edifício central se encontrar encerrado, o plenário realizou-se na praça da Porta Férrea tendo usado da palavra vários professores e alunos, que decidiram que uma comissão se deslocasse ao Quartel-General, a fim de pedir às Forças Armadas essa demissão, tomando os membros da comissão a responsabilidade pelos bens e pessoas demitidos. Entretanto, um grupo de estudantes detiveram o guarda do edifício da Faculdade de Medicina, Manuel Pinto Baptista, que sempre foi acusado de informador e colaborador da PIDE/DGS, tendo assim contribuído para a prisão de muitos estudantes. (DIÁRIO DE LISBOA, 30 de abril de 1974, p. 15).
\end{abstract}

Como evidencia o excerto, os estudantes assumiram um papel de primeira ordem na decomposição do regime anterior procurando identificar todos aqueles que estivessem ligados ao regime deposto. A realização de Assembleias Gerais aconteceram um pouco por todo o país havendo, inclusivamente, perseguições a elementos conotados com o Estado Novo. (HENRIQUES, 2012).

De qualquer dos modos, defendemos, à semelhança de Pintassilgo (2015), que o período consequente à Revolução do 25 de Abril de 1974 constituiu um momento de muitas experiências, esperanças e utopias, sobretudo no campo educativo:

O ambicioso projeto de construir uma sociedade nova, uma escola nova, um homem novo estava presente nos discursos de muitos dos atores. Neles conviviam, de forma aparentemente paradoxal, tanto a crença messiânica na transformação operada pelo momento mágico representado pelo 25 de Abril como a conviç̧ão de que se tornava necessário investir nessa construção do novo, designadamente por via da transformação da educação, parte integrante de uma assumida «revolução cultural». Outro dos traços característicos das conceções então prevalecentes era a íntima relação estabelecida entre os registos pedagógico e político-ideológico. A tese de que a política é transversal, estando presente em todos os domínios da vida social foi assumida sem complexos. A escola, nesta perspetiva, não era nem poderia ser neutral. Ela deveria contribuir para a construção de uma sociedade socialista. (PINTASSILGO, 2015, p. 15).

É neste contexto, de orientação da Escola para uma via socialista, construída pelos 
diversos Governos Provisórios, que pretendemos realçar as correntes discursivas associadas à universidade portuguesa através, em particular, da imprensa diária nacional.

\section{Diário de Lisboa: construindo a opinião pública sobre a Universidade Portuguesa}

Os períodos de mudança ao longo da modernidade implicam reconfigurações várias nos diferentes discursos colocados em circulação. Essas reconfigurações assumem um único objetivo: atingir o individuo de modo a controlar/transformar a sua ação através, muitas vezes, das narrativas circulantes. Neste processo, o Estado é parte interessada em influenciar a opinião pública criando para o efeito os "discursos oficiais" que assumem maior legitimidade junto da sociedade dado que são proferidos em nome de todos - isto é do "universal" - tomando-se como verdades incondicionais e, por isso, não questionando a sua origem e muito menos a figura do próprio Estado.

A construção da opinião pública é um processo realizado através de um conjunto de discursos que pretendem ser dominantes e, desse modo, consensualizar a "opinião de todos". Porém, "a opinião de todos" não é senão mais que o resultado da opinião de poucos mandatados que pretendem dominar a chamada "sociedade civil" e construir uma opinião pública conformada áquilo que é o pensamento de um grupo mais ou menos dominante. (BOURDIEU, 2014). É neste contexto que a imprensa diária surge como um importante instrumento de transmissão de opinião sobre os mais diversos assuntos, entre eles as questões relacionadas com o campo da Educação.

Em termos práticos, a imprensa diária constitui uma fonte documental ainda pouco utilizada de um modo sistemático. Não obstante, esta apresenta potencialidades enormes que permitem reconhecer problemas de uma determinada época, relações de poder, evidenciar correntes ideológicas e caraterizar quotidianos que, por isso, contribuem decisivamente para ampliar a compreensão critica sobre as épocas estudadas. É exatamente neste sentido que Hernández Huerta \& Ortega Gaite (2015) nos chamam a atenção quando afirmam:

[...] daily press, a repository of fresh and rich material with notable explicative and interpretative potential. Such archive makes it possible, among other things, to explore the prevailing mentalities, ideologies and collective pedagogical imaginaries that both condition and are conditioned by a particular time and space, to explore spheres of the history of education that are not contained in nor exhausted by official registers, to reconstruct part of quotidian educational occurrences, to bring into relief the interest focus and priorities of the media, and to clarify, delimit and analyse currents of public opinion. $(2015$, p. 364$)$.

Partindo dos pressupostos colocados no excerto anterior, procuraremos evidenciar e problematizar as principais temáticas relacionadas com a universidade portuguesa presentes na imprensa diária em Portugal através do estudo do Diário de Lisboa no período correspondente à transição para a democracia (1974-1976). Os discursos que apontamos a seguir permitiram construir um determinado sentido na opinião pública sobre a necessidade de renovação da estrutura universitária, em articulação com a afirmação da democracia, apontando como solução o socialismo democrático.

No decorrer da análise efetuada identificamos 4 categorias axiais que se integram no processo global de democratização da sociedade portuguesa e, em particular, das suas 
estruturas de ensino e investigação como é o caso da Universidade. A primeira categoria prende-se com a "desfascização" do ensino superior; a segunda, com o acesso ao ensino superior; a terceira, com as práticas pedagógicas e os modelos de avaliação no ensino superior; a quarta, com a necessidade de renovação da Universidade e a emergência de novas configurações universitárias em Portugal.

No que diz respeito ao processo de "desfascização" da Universidade portuguesa, a necessidade de quebrar com as características e orientações do passado no interior da Universidade em Portugal surgem como elementos presentes em permanência ao longo do estudo realizado. Os ideais associados ao regime político anterior, que circulavam no sistema educativo, deveriam, com a maior rapidez possível, ser afastados a todo o custo. A este propósito, é comum encontrar na imprensa diária noticias e/ou artigos que reproduzem o discurso oficial (como o excerto do despacho do Ministério da Educação e Cultura que a seguir evidenciamos) revelando, por exemplo, a urgência de substituir os manuais escolares das crianças mais novas.

A queda do regime fascista e o processo de democratização que se iniciou em Portugal, em 25 de Abril, tornaram inutilizáveis, na sua maior parte, os programas do ensino básico e secundário, uma vez que esses programas visaram, no seu conjunto a conformação com a ideologia do regime deposto, sofriam de graves distorções, impostas por motivos políticos e estavam eivados de um espirito anacrónico em oposição flagrante muitas vezes com a atitude científica e a abertura da criação cultural ao mundo moderno. (DIÁRIO DE LISBOA, 17 de Setembro de 1974, p. 17).

Também estes problemas, embora com outras configurações, existiam nas universidades portuguesas. Era necessário converter os princípios e a sua ação pedagógica de modo a responder ao novo momento político-educativo. A "desfascização" da Universidade portuguesa constituiu um dos maiores desígnios daquele tempo, com representação permanente no Diário de Lisboa. A necessidade de mudar a universidade e adequá-la ao novo projeto político de caráter socialista, que se tentava implementar em Portugal, constituía uma das grandes preocupações expressas pelos meios de comunicação no processo de construção da opinião pública da época.

A democratização da estrutura universitária portuguesa encontrou em Vitorino Magalhães Godinho² um elemento fundamental à construção de uma retórica renovadora para a Universidade num tempo também ele de mudança. $O$ então Ministro da Educação afirmava convictamente que:

A opinião pública tem que aperceber-se do papel que a educação e a cultura desempenham necessariamente na criação de um novo Portugal. Tem ainda o direito de saber o destino que é dado aos dinheiros públicos, fruto do trabalho das classes operárias camponesas e de todos os quadros técnicos, e de todos quantos contribuem para a criação da riqueza nacional. Tem ainda essa opinião de tomar consciência da situação presente e de conhecer os rumos do porvir pela necessidade de trabalho árduo que se impõe a todos nós dado o fardo extremamente pesado da herança que nos foi legada. (GODINHO, 1974, p. 11).

A consciência do papel que a Educação deveria ter está aqui bem ilustrado quando

\footnotetext{
2 Vitorino Magalhães Godinho foi ministro da Educação nos tempos mais conturbados do Prec (17 de Julho a 29 de Novembro de 1974).
} 
Magalhães Godinho procurava esclarecer, através da imprensa, os portugueses sobre o novo sentido e atitude que deviam adotar. Alimentou a ideia de que a opinião pública podia ter uma palavra a dizer sobre os caminhos a seguir, devendo ser de um modo fundamentado e esclarecido, contribuindo para a efetiva democratização de Portugal. Defendeu que a escola isoladamente não conseguiria aprofundar o processo de democratização da sociedade portuguesa, mas que podia contribuir de um modo efetivo se as estruturas políticas, e a opinião pública, valorizassem, desde logo, a educação infantil, a educação permanente ou a adequação da Universidade. Neste sentido, procurou afirmar a seguinte ideia:

Democracia não é incompetência. Pelo contrário, a democracia é o regime dos competentes, daqueles que não foram selecionados pelos recursos materiais da família ou por circunstâncias particulares da sua existência, por favoritismos daqueles que foram encarreirados para as funções onde podem melhor contribuir para o bem comum e realizar a sua personalidade por uma seleção que não é um sistema de obstáculos, mas sim o melhor aproveitamento dos recursos humanos para aproveito de todos. (GODINHO, 1974, p. 11).

O excerto anterior é representativo do papel que a Educação podia ter neste processo de transição para a democracia. A Universidade, em particular, deveria constituirse como fiel depositária do princípio da igualdade independentemente do berço onde nasceram os seus estudantes. Este é, provavelmente, um dos maiores desígnios da democratização da sociedade e da Universidade em Portugal. É por isso que encontramos em permanência textos diversos que colocam a Universidade como uma arena da luta de classes entre uma burguesia instalada, associada ao regime politico anterior, e a necessidade de abrir a universidade aos filhos de camponeses e operários permitindo o acesso ao ensino superior e a sua mobilidade social. De acordo com Ferreira (1994):

\footnotetext{
Travou-se, então, uma formidável luta institucional em Portugal [...]. As classes sociais em Portugal encontravam-se ainda à procura de melhores instrumentos de intervenção política, e não seria para admirar que assim fosse, dado que o regime da ditadura não havia permitido o desenvolvimento autónomo dos grupos sociais, espartilhando-os na ordem corporativa estatal e legislando no cerceamento do direito de associação. Desta maneira, partidos políticos, sindicatos, comissões de trabalhadores, cooperativas, grupos de pressão, assim como organizações tais como as igrejas, lojas maçónicas, universidades e até os grandes corpos do Estado só puderam desenvolver-se naturalmente após a queda da ditadura, o que veio tornar extremamente aguda a luta entre essas diferentes instituições para afirmarem o seu poder e influência, não só nas áreas respectivas, como também, para algumas, na tentativa de alcançarem a hegemonia do poder político em Portugal. Assim, a construção do Estado esteve dependente do apuramento final das instituições ordenadoras e transmissoras da vontade popular e dos interesses sociais. (1994, p. 223).
}

A possibilidade de intervenção política, negada durante décadas à maioria dos portugueses, transformou o período em análise num momento extremamente rico da História Contemporânea Portuguesa. Em particular, no que respeita à Universidade, afirmava-se na altura a necessidade de "abolir uma determinada linguagem elitista" no seu interior conformando-a aos novos públicos que haviam de passar a frequentá-la. Para o efeito tornava-se necessário "modificar o diálogo" que ali continuava a circular: 
Mais importante do que fazer aceder os filhos das classes trabalhadoras à Universidade, mais importante, antes disso, é modificar por completo o próprio diálogo pedagógico das Universidades. Antes de se meterem operários nas faculdades, sob a pena de ser um fracasso, é preciso modificar a programação pedagógica das universidades porque se o operário vai entrar para uma Faculdade como está agora, em diálogo pedagógico, em relações sociais e pessoais como elas se geram neste momento, o mais certo é que o operário se frustará. A maior parte dos programas que lá se tratam não tem nada a ver com os seus problemas. E até o próprio estilo da linguagem que se utiliza nas universidades não é de maneira nenhuma em termos de comunicação social, a linguagem do operário. (HESPANHA, entrevista ao Diário de Lisboa, 04 de setembro de 1975, p. 10).

O trabalho de democratização da Universidade foi longo. Note-se que o excerto anterior, resultante de uma entrevista cedida ao Diário de Lisboa, foi publicado em Maio de 1975, cerca de um ano após o golpe militar do 25 de abril de 1974, indiciando o conjunto de dificuldades em mudar aquilo que estava estabelecido há muitos anos cuja origem se situava no regime político deposto ${ }^{3}$. É a relação de forças entre uma universidade tradicional e o projeto de construção de uma nova universidade, de acordo com um novo projeto político, que se encontra aqui em causa.

A construção de um novo modelo de universidade com caraterísticas diferentes daquelas conhecidas até esse momento tornou-se uma parte fundamental do novo regime político democrático português. Na verdade, faz parte desse processo a modificação das estruturas de gestão das instituições. De acordo com Torgal (2015):

[...] verificou-se então a mudança de reitores das universidades e de directores das faculdades e uma tentativa de "saneamento" de professores considerados "fascistas" em assembleias gerais de faculdades, que, na prática acabaram por não ser demitidos, perdendo, todavia, o ténue vínculo às instituições alguns assistentes, isto é, os docentes que tinham uma ligação mais precária às suas escolas e que apoiavam o serviço docente de professores catedráticos. Ao mesmo tempo, autoconstruíam-se novos currículos escolares por comissões ad hoc, bem marcados, sobretudo nas áreas de ciências sociais, pela ideologia marxista. Neste contexto, verificaram-se muitas aparentes "mudanças ideológicas". (2015, p. 160).

Nesta altura os protagonistas universitários sofreram muitas alterações num processo conturbado e de transição. É também neste período que passamos a encontrar preocupações efetivas em descentralizar o "poder" das instituições de ensino universitário. Para 0 efeito, foram, em velocidades diferentes, criados órgãos gestionários como a Assembleia de Escola, enquanto órgão representativo da estrutura universitária no seu conjunto; o Conselho diretivo, cuja missão estava mais vocacionada para o governo orçamental da instituição; o Conselho Pedagógico, fundamental em qualquer instituição democrática pelos debates que ali se desenvolviam em torno da matéria pedagógica; e, por fim, o Conselho Cientifico, um órgão de matriz mais consultiva direcionado, numa fase inicial, para provas académicas, júris, entre outros aspetos (DIÁRIO DE LISBOA, 31 dezembro de 1974, p. 12). Esta nova orgânica institucional deveria assumir o processo de democratização das instituições através de uma participação efetiva de todos os que desejavam colaborar e participar ativamente na construção de uma nova instituição e sociedade. Em nosso entender é a capacidade de mobilização das pessoas que constitui a marca fundamental deste período independentemente das opções político-ideológicas.

${ }^{3}$ Cf. Hespanha, 18971/2. 
Um segundo elemento que surge com relevância no Diário de Lisboa no período em análise prende-se com o acesso ao ensino superior. De acordo com António Hespanha o acesso às universidades deveria corresponder ao processo maior de democratização da sociedade portuguesa e, em particular, ao papel das universidades nesse processo. Para o efeito, realça a importância de corrigir "a origem social dos universitários" evidenciando a necessidade de permitir o acesso às classes trabalhadoras; o alargamento institucional das universidades a espaços mais deprimidos (nomeadamente no interior do país); e, afirmava, a ideia da existência de uma "revolução cultural no meio estudantil" procurando colocar em contacto os candidatos a estudantes universitários com as diferentes realidades do país (HESPANHA, 1975, p. 10). Neste sentido, procuraram-se implementar diversas experiências nas Universidades portuguesas. Entre elas, e no seguimento da edificação de uma sociedade de cariz socialista, destacamos o chamado "serviço cívico". O "serviço cívico" constituía uma oportunidade de colocar em contacto os públicos candidatos à frequência de uma universidade com as comunidades regionais e locais. Ao longo das publicações analisadas foram vários os textos que colocavam em destaque esta discussão. De um lado, aqueles que defendiam o serviço cívico como um facto de construção de uma sociedade mais justa e socialista. Do outro lado, aqueles que consideravam não ser esta a melhor via para a construção da democracia portuguesa. No fundo a discussão evidenciada pelo Diário de Lisboa representa a luta de classes que se fez sentir naquele período com maior intensidade. A este propósito, o Diário de Lisboa publica a 2 de janeiro de 1975 um ponto de situação, assinado por Rogério Rodrigues, relativamente às problemáticas em que o "serviço cívico" esteve envolvido:

Em 11 de Novembro de 1974, o prof. Pereira de Moura em entrevista concedida ao D.N., informa da necessidade e utilidade do serviço cívico estudantil. A contestação começa. Os exames à aptidão são boicotados em cinco faculdades do país. Em 28 de Novembro, Vitorino Magalhães Godinho demite-se. A sua entrevista à "Vida Mundial" põe o dedo na ferida. A contestação agrava-se como manutenção de situações de privilégio. A 14 de Fevereiro abrem as inscrições para o serviço cívico, que arrancará só em Setembro. O IV governo institucionaliza-o. [...] o serviço cívico era uma forma de seleção burguesa. (RODRIGUES, 1976, p. 8).

Como evidencia o excerto anterior o acesso ao ensino superior e a existência de um ano propedêutico que se propunha, no essencial, valorizar a reflexão em articulação com a ação, a teoria com a prática ou ainda o trabalho intelectual e o trabalho manual contribuiu para uma discussão alargada direcionada, sobretudo, para a construção de um processo de seleção dos alunos candidatos ao ensino superior mais justo, inclusivo e promotor da igualdade de oportunidades para aqueles que até aí não tinham podido frequentar as instituições universitárias. Parece ser uma luta entre a burguesia e o operariado que o Diário de Lisboa evidencia nas suas páginas ao longo do período de transição para a democracia.

Por outro lado, e em terceiro lugar, as referências no Diário de Lisboa remetem-nos também para a vida interna das instituições universitárias. Procurava-se transmitir a ideia de que era preciso modificar os modos de ensinar e de avaliar os estudantes no novo contexto sociopolítico português. A este propósito foi necessário introduzir instrumentos moralizadores de uma situação difícil de controlar no interior das instituições universitárias. Procedeu-se a uma simplificação da avaliação dos estudantes, sem prejuízo da afirmação da capacidade do docente nesse processo, transformando-a nas classificações de "Apto" 
e "Não Apto".

Efetivamente, foi necessário "moralizar" os excessos da revolução no campo educativo, sobretudo no que respeita aos processos de avaliação. A 26 de julho de 1975 foi publicado um comunicado do Ministério da Educação e Investigação Cientifica onde se reconhecia a "situação caótica" a que se tinha chegado, dando-se a conhecer as novas formas de avaliação com o objetivo de estabilizar a vida de professores e alunos.

O comunicado estabelece certas normas mínimas relativas aos critérios de
avaliação do aproveitamento escolar dos alunos do ensino superior. «As razões que
motivam esta decisão quanto à tabela de classificação baseiam-se, no facto de, não
vivendo as escolas divorciadas da sociedade em que estão implantadas, se dever
ter em consideração a estrutura nesta vigente no que se refere ao provimento e
promoção profissional das pessoas bem como à avaliação dos méritos de cada um
[...]. Segundo as novas normas, avaliação é da responsabilidade dos docentes e só
serão válidas as provas em que os responsáveis pelas disciplinas tenham voto
decisivo. (DIÁRIO DE LISBOA, 26 de julho de 1975, p. 16).

Também esta decisão gerou discórdia e provocou nos estudantes reações mobilizando manifestações que procuravam o esclarecimento sobre este novo modelo de avaliação. Desta realidade controversa e complexa dá-nos conta Torgal (2015) quando afirma:

Desta tentativa, e dos movimentos estudantis radicais que surgiram, aproveitaramse, de forma oportunista, muitos estudantes que tiveram uma «passagem administrativa", ou seja, uma aprovação automática que Ihes foi concedida no final do ano lectivo de 1973/1974, ao mesmo tempo que terminava nas Faculdades de Letras a tese de licenciatura, o que acabou por criar muitos "licenciados" que até aí eram apenas considerados "bacharéis". (TORGAL, 2015, p. 160).

Por fim, destacamos em quarto lugar, a emergência de novas configurações universitárias em Portugal, como sinal dos novos tempos que se pretendiam instalar. Neste processo de mudança que decorreu entre 1974 e 1976 surgiram novas instituições universitárias com configurações próprias permitindo alargar a noção de democratização do ensino superior. Foi o caso, entre outras, da Universidade do Minho, da Universidade Aberta (com metodologias de ensino à distância) ou mesmo da Universidade da Beira Interior ou de Évora. Um novo projeto político exigiu novas instituições universitárias que contribuíssem para desenvolver o modelo de sociedade proposto naquela época: uma nova sociedade socialista e democrática, como ficou plasmado na Constituição da República Portuguesa aprovada em Abril de 1976. Como afirmava Ramos (1974) "estas e outras universidades permitirão uma igualdade de oportunidades, facultando a frequência de todos os jovens que até aqui, por falta de meios materiais, não tinham oportunidade de frequentar estudos superiores" (ano, 54, n 18505, 8 de julho, p. 19). Efetivamente, iniciava-se um ciclo novo em Portugal com a abertura de mais universidades criando-se mais oportunidades entre homens e mulheres, promovendo uma sociedade um pouco mais justa e livre, onde as ideias passaram a constituir um elemento de força e de renovação de uma sociedade que esteve submissa durante quase cinco décadas.

\section{Considerações finais}

O período que se seguiu à deposição do regime autoritário português, em 1974, 
caraterizou-se pela substituição, em cerca de 30 países na Europa, Asia e América Latina, além de outros movimentos democratizadores que surgiram um pouco por todo o mundo, de regime autoritários por regimes democráticos. (HUNTINGTON, 1993, p. 21). Iniciou-se um tempo onde a democracia constituiu a esperança libertadora de um passado ancorado a formas de violência física e psicológicas permanentes.

Em Portugal, o período decorrido entre abril de 1974 e abril de 1976 constituiu um momento de transição revolucionária para a democracia. Época de muitos sonhos e utopias, de emergência de forças políticas diversas, com olhares plurais no que respeita ao modelo de sociedade a implementar em Portugal, época de transformação e mudança que nos implica até aos dias de hoje.

A Educação constituiu um campo de lutas e de tensões permanentes uma vez que foi através da Escola que se construiu e/ou implementou um novo paradigma socioeconómico e político. No período de transição revolucionária para a democracia a Universidade portuguesa constituiu-se como um palco privilegiado de mudança. Afastaramse reitores e professores, somaram-se reivindicações de movimentos estudantis, as forças políticas e sindicais entraram na universidade, enfim, transformou-se e colocou-se em causa a Universidade como até aí tinha existido - tradicional - e procurou-se colocar esta instituição ao serviço de uma sociedade nova que se pretendia socialista democrática. Deposto o regime autoritário a universidade depressa procurou associar-se ao Movimento das Forças Armadas procurando interiorizar a mudança preconizada pelos "jovens militares". Apresentou-se como uma parte da solução para tornar mais rápido o processo de democratização da sociedade portuguesa e constituiu-se como garantia e mecanismo de construção de uma sociedade mais igual onde as oportunidades de ensino deveriam democratizar-se permitindo a todos aqueles que o pretendessem frequentar aquelas instituições.

Para atingir o fim proposto, expresso na imprensa diária, era necessário agir em quatro frentes, relacionadas e articuladas entre si: por um lado, era preciso "retirar" o fascismo do interior das instituições universitárias. Para isto, era preciso afastar todos aqueles que se encontravam conotados com o regime político anterior e proceder à democratização das instituições através, entre outros aspetos, da implementação de uma gestão democrática onde todos podiam, e deviam, ter uma voz ativa. Do mesmo modo, tornava-se urgente abrir as instituições universitárias a outros públicos nomeadamente àqueles que nunca tiveram a oportunidade de a frequentar acrescentando, assim, uma maior possibilidade de mobilidade social. Além disto, era preciso reavaliar os processos de avaliação dos estudantes à luz dos novos princípios norteadores da ação institucional. E, por fim, tornou-se necessário não apenas modificar o que existia, mas também fundar novas instituições universitárias que respondessem cabalmente às ideias do modelo social que pretendia instalar-se e vingar em Portugal.

A crença na mudança e a esperança na construção de um país melhor basearamse nos princípios onde assenta qualquer democracia: numa cultura de negociação permanente, compromissos e entendimentos além, claro está, da existência de um governo eleito pelos cidadãos, que lidera mas que deve responder perante um texto fundamental como a constituição democrática. Como afirma Huntington (1993) "compromisse, elections, and nonviolence were the third wave democratization syndrome" (p. 165).

Em suma, a implementação de um novo paradigma associado ao socialismo 
democrático em Portugal implicou fortemente as universidades no processo de transição para a democracia. Este processo foi potenciado através da imprensa diária nacional, de que é exemplo o Diário de Lisboa, que foi dando conta do que se passava nestas instituições permitindo-nos compreender a centralidade da Educação nas suas páginas e ampliar esta leitura para o contexto social da época. A universidade foi um enorme palco de circulação de poderes, ideias, permanências e mudanças quer serviu Portugal num processo de transição do Estado Novo para o novo regime político português: a democracia.

\section{Referências}

ALVES, Manuela. Contrariando o processo de democratização - Manuais do Ensino Primário Servem a Causa do Fascismo. Diário de Lisboa, 54 (18584), p. 11, 11 out. 1974.

AVRITZER, Leonardo. Cultura política, atores sociais e democratização: uma crítica às teorias da transição para a democracia. RBCS, 10 (28), 1995. Disponível em: <http://www.anpocs.org.br/portal/publicacoes/rbcs_00_28/rbcs28_09.htm>

BOURDIEU, Pierre. Sobre o Estado - Curso no Collége de France (1989-1992). Lisboa: Edições 70, 2014.

DIÁRIO DE LISBOA. A massa estudantil adere ao movimento. 54 (18444), p. 18, 30 abr. 1974.

A propósito da gestão das universidades. 54 (18652), p. 12, 31 dez. 1974.

Afastar o fascismo do ensino. 54 (18558), p. 17, 17 set. 1974.

Decreto-Lei do MEC - A propósito da gestão das universidades. 54 (18652), p. 12, $31 \mathrm{dez} .1974$.

Ensino Superior - Normas novas para avaliação de conhecimentos. 55 (18825), p. 16, 26 jul. 1975.

Normas novas para avaliação de conhecimentos. 55 (18825), p. 16, 26 jul. 1975.

Pedida a demissão do Reitor da Universidade. 54 (18444), p. 15, 30 abr. 1974.

FERNANDES, Rogério. Educação: uma frente de luta. Lisboa: Livros Horizonte, 1977.

Rui Grácio: uma pedagogia da emancipação. In: GRÁCIO, R. Obra completa. I Da educação. Lisboa: Fundação Calouste Gulbenkian, 1995.

FERREIRA, José Medeiros (Coord.). História de Portugal - Portugal em Transe. v. VIII. Lisboa: Editorial Estampa, 1994.

GODINHO, Vitorino Magalhães. Que todos os portugueses participem no projecto nacional de educação. Diário de Lisboa, 54 (18519), p. 11, 24 jul. 1974.

GRACIO, Rui. O congresso do ensino liceal e os grupos de estudo do pessoal docente do ensino secundário. Análise Social, 19 (77-78-79), p. 757-779, 1983.

Obra completa. II - Do Ensino. Lisboa: Fundação Calouste Gulbenkian, 1995.

HENRIQUES, Helder Manuel Guerra. Formação, sociedade e identidade profissional dos enfermeiros: a Escola de Enfermagem de Castelo Branco/Dr. Lopes Dias (19481988). 2012. Tese (Doutoramento) - FPCE - UC. Coimbra, 2012. Disponível em: <http://hdl.handle.net/10316/19075>.

HENRIQUES, Helder; MARCHAO, Amélia; MOURATO, Joaquim. A democracia e o 
ensino superior politécnico português: o caso do Instituto Politécnico de Portalegre (década de 80 do séc. XX). Espacio, Tiempo y Educación, 2 (2), p. 173-196, 2015. HERNÁNDEZ HUERTA, José Luis; GONZÁLEZ GÓMEZ, Sara. Opinión pública y educación durante la transición a la democracia en Argentina. Primeras consideraciones y guía de fuentes documentales. Educació i història: Revista d'història de l'educació, 24, p. 173-215, 2014.

HERNÁNDEZ HUERTA, José Luis; ORTEGA GAITE, Sonia. Civic Education and public opinion in Argentina during the transition to democracy (1982-1983). History of Education \& Children's Literature, 10 (2), p. 359-389, 2015.

HESPANHA, António M. Estas vozes que nos vêm do "antigamente". Diário de Lisboa, 55 (18971), p. 1-2, 6 fev. 1976.

. O Acesso à Universidade. Diário de Lisboa, 55 (18894), p. 10, 16 out. 1975.

Temos de abolir a linguagem elitista da universidade. Diário de Lisboa [Entrevista], 55 (18858), p. 10-11, 4 set. 1975.

HUNTINGTON, Samuel P. The third wave: democratization in the late twentieth century. Norman: University of Oklahoma press, 1993.

NÓVOA, António. A educação nacional. In: ROSAS, Fernando (Coord.). Portugal e o Estado Novo (1930-1960). v. XII, p. 456-519. Lisboa: Presença, 1992.

PINTASSILGO, Joaquim. A Educação em tempos de Revolução (nos 40 anos da Revolução do 25 de Abril de 1974 em Portugal). Espacio, Tiempo y Educación, 1 (2), p. 13-19, 2014.

PINTASSILGO, Joaquim; MOGARRO, Maria João. A ideia de Escola para todos no pensamento pedagógico português. In: PINTASSILGO, Joaquim; FERNANDES, Rogério. A modernização pedagógica e a escola para todos na Europa do sul no século XX. Lisboa: CIEFCUL \& UIDCE-FPCEUL, 2003. p. 51-71.

Programa de acção do Ministério da Educação e Investigação Científica (MEIC) do IV Governo Provisório. Revista Lusófona de Educação, 10, 2007, p. 142-154.

RAMOS, Armindo Matos. Reforma de ensino que põe em risco uma ditadura. Diário de Lisboa. 54 (18505), p. 19, 8 jul. 1974.

RODRIGUES, Rogério. Abre em Greve, Termina em Notas. Diário de Lisboa, 55 (18941), p. 8-9, 2 jan. 1976.

STOER, Stephen. Educação e mudança social em Portugal. Porto: Edições Afrontamento, 1986.

TEODORO, António. A construção política da educação. Estado, mudança social e políticas educativas no Portugal contemporâneo. Porto: Edições Afrontamento, 2001.

TORGAL, Luís Reis. A universidade em Portugal em período de transição para a democracia e para o neoliberalismo. Espacio, Tiempo y Educación, 2 (2), p. 155-171, 2015.

VALENTIM, J. P. Escola, igualdade e diferença. Porto: Campo das Letras, 1997. XAVIER, Libania Nacif. Os movimentos docentes brasileiro e português na virada dos anos 1970-80. Revista Tempo e Argumento, 5 (10), p. 234-257, 2013. 
HELDER MANUEL GUERRA HENRIQUES é professor adjunto no Instituto Politécnico de Portalegre (Portugal) e investigador no Centro de Estudos Interdisciplinares do Século XX Grupoede - da Universidade de Coimbra, Doutorado e Pós-doutorado em Ciências da Educação, na especialidade em História da Educação, pela Universidade de Coimbra.

Endereço: Escola Superior de Educação e Ciências Sociais - Praça da República, 23-25 7300109 - Portalegre - Portugal.

E-mail: henriqueshelder@gmail.com

Recebido em 02 de outubro de 2017.

Aceito em 28 de novembro de 2017. 